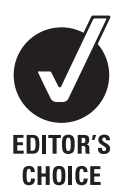

${ }^{1}$ Department of Biomedical Sciences and Human Oncology, University of Turin, Turin, Italy ${ }^{2}$ Cancer Research UK, London Research Institute, London, UK ${ }^{3}$ Molecular Pathology Team, The Breakthrough Breast Cancer Research Centre, Institute of Cancer Research, London, UK

\section{Correspondence to}

Jorge S Reis-Filho, The

Breakthrough Breast Cancer Research Centre, Institute of Cancer Research, 237 Fulham Road, London SW3 6JB, UK; jorge.reis-filho@icr.ac.uk

Accepted 27 November 2009

\title{
Adenoid cystic carcinomas of the breast and salivary glands (or 'The strange case of Dr Jekyll and Mr Hyde' of exocrine gland carcinomas)
}

\author{
Caterina Marchiò, ${ }^{1}$ Britta Weigelt, ${ }^{2}$ Jorge S Reis-Filho ${ }^{3}$
}

\begin{abstract}
Adenoid cystic carcinoma (AdCC) is a tumour with myoepithelial differentiation and characterised by the presence of a dual population of basaloid and luminal cells arranged in specific growth patterns. These tumours, regardless of the anatomical site, are characterised by expression of the proto-oncogene and therapeutic target c-KIT, and seem to harbour a specific chromosomal translocation $t(6 ; 9)$ leading to the fusion gene MYB-NFIB and overexpression of the oncogene $M Y B$. However, the clinical behaviour of salivary gland and breast AdCC differs; while salivary gland lesions have a relatively high proclivity to metastasise, patients with breast AdCCs have an excellent outcome. Here the clinical, morphological and molecular features, and potential therapeutic targets of salivary gland and breast AdCCs are reviewed.
\end{abstract}

\section{INTRODUCTION}

Adenoid cystic carcinomas (AdCCs) are among the most common salivary gland malignancies but also affect other exocrine tubulo-acinar glands ${ }^{1-7}$ such as the breast. $^{8}$ Despite the long recognised morphological similarities of tumours arising in these two glandular structures and the fact that these tumours harbour a recurrent chromosomal translocation, ${ }^{9}$ AdCCs of the salivary glands and the breast differ in incidence and clinical behaviour. Here, we review the clinical, morphological and molecular features, and potential therapeutic targets of salivary gland and breast AdCCs.

\section{DEFINITION, CLASSIFICATION AND OVERVIEW OF ADENOID CYSTIC CARCINOMAS}

The term cylindroma, the pathological entity later called 'adenoid cystic carcinoma', was coined by Billroth $^{10}$ to describe a salivary gland tumour composed of entwined cylinders of hyaline stroma and epithelial cells (indeed the illustrations from Billroth's study ${ }^{10}$ depict the typical architectural pattern of cylindromas/AdCCs, and the cribriform structures with pseudoglands found in AdCCs. The term adenoid cystic carcinoma (carcinoma adenoides cysticum) of the salivary glands was first used by Ewing (1919) ${ }^{11}$ and applied by Geschickter in 1945 to tumours of the breast. ${ }^{12}$ Since then, AdCCs have also been described in several other organs such as lacrimal glands, auditory canal, upper respiratory tract and lung, digestive tract, skin, prostate and lower female genital tract. ${ }^{1-7}$

AdCC belongs to the subgroup of tumours of the myoepithelial lineage and is defined as a tumour where both epithelial (luminal) and myoepithelial (basaloid) cells are neoplastic (figure 1). Multiple architectural patterns have been reported (eg, cribriform, tubular, trabecular and solid) in both mammary and salivary glands, and generally a mixture of different growth patterns are found in AdCCs. ${ }^{1}{ }^{14}$ The cribriform growth pattern is the most characteristic and features variably sized and usually smoothly contoured islands of neoplastic cells arranged to compose pseudolumens (which are not true glandular lumens but represent stromal invaginations) and true glandular spaces (formed by the epithelial cells) giving rise to a 'sieve-like' appearance (figure 1). ${ }^{114}$ These spaces are filled with eosinophilic hyaline material (Periodic acid-Schiff (PAS) positive, diastase resistant), and/or lightly basophilic myxoid substance (Alcian blue positive): these materials have been demonstrated to represent duplicated basal lamina and glycosaminoglycans by ultrastructural studies (see Cheuk and Chan ${ }^{1}$ and Bennett et $a l^{15}$ and references therein). Within the cribriform islands, there are occasional true narrow glands lined by cuboidal cells with eosinophilic cystoplasm ${ }^{1}$ (see figure 1). Histological variants are the glandular (or tubular), reticular (or trabecular) and solid growth patterns (figure 1). The tubular variant is characterised by glandular spaces of elongated tubules lined by epithelial cells and surrounded by single or multiple layers of basaloid cells; the glandular lumens are either empty or contain secretion. In the trabecular variant cells are arranged to form small nests, ${ }^{14}$ whereas the solid variant is composed of island and sheets of closely packed basaloid cells, with very few or even no pseudocystic spaces; few true glandular spaces can be found. ${ }^{1}$

The two distinct cells types of AdCCs, basaloid and luminal, are best appreciated by immunohistochemical staining (table 1). The basaloid cells express basal cytokeratins (Cks) such as Ck14 and Ck17, vimentin, S-100 protein, actin, calponin and p63. In addition, strong nuclear and cytoplasmic immunoreactivity of maspin, a mammary inhibitory serine protease, has been described in the myoepithelial component of a series of AdCCs of the breast. ${ }^{16}$ The epithelial cells show strong positivity for luminal cytokeratins such as $\mathrm{Ck} 7$, for CEA, EMA and CD117 (c-KIT). ${ }^{1} 817$

The stromal hyaline material is best highlighted by staining for collagen IV and laminin. In addition, PAS and Alcian blue staining may help differentiate the material present in true glandular lumens and pseudolumen, respectively (see above). ${ }^{1} 8$ 
Figure 1 Representative micrographs of the different variants of adenoid cystic carcinoma (AdCC). Breast AdCC showing a mixture of cribriform (A), tubular (B), trabecular (C) and solid (D) growth patterns. Examples of grade 1 (I), grade 2 (II) and grade 3 (III) AdCCs, according to the grading system proposed by Ro et al..$^{13}$

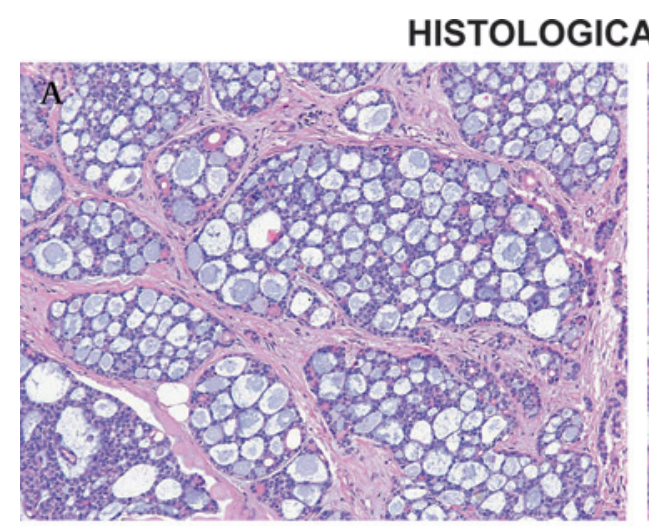

\section{AL SUBTYPES}
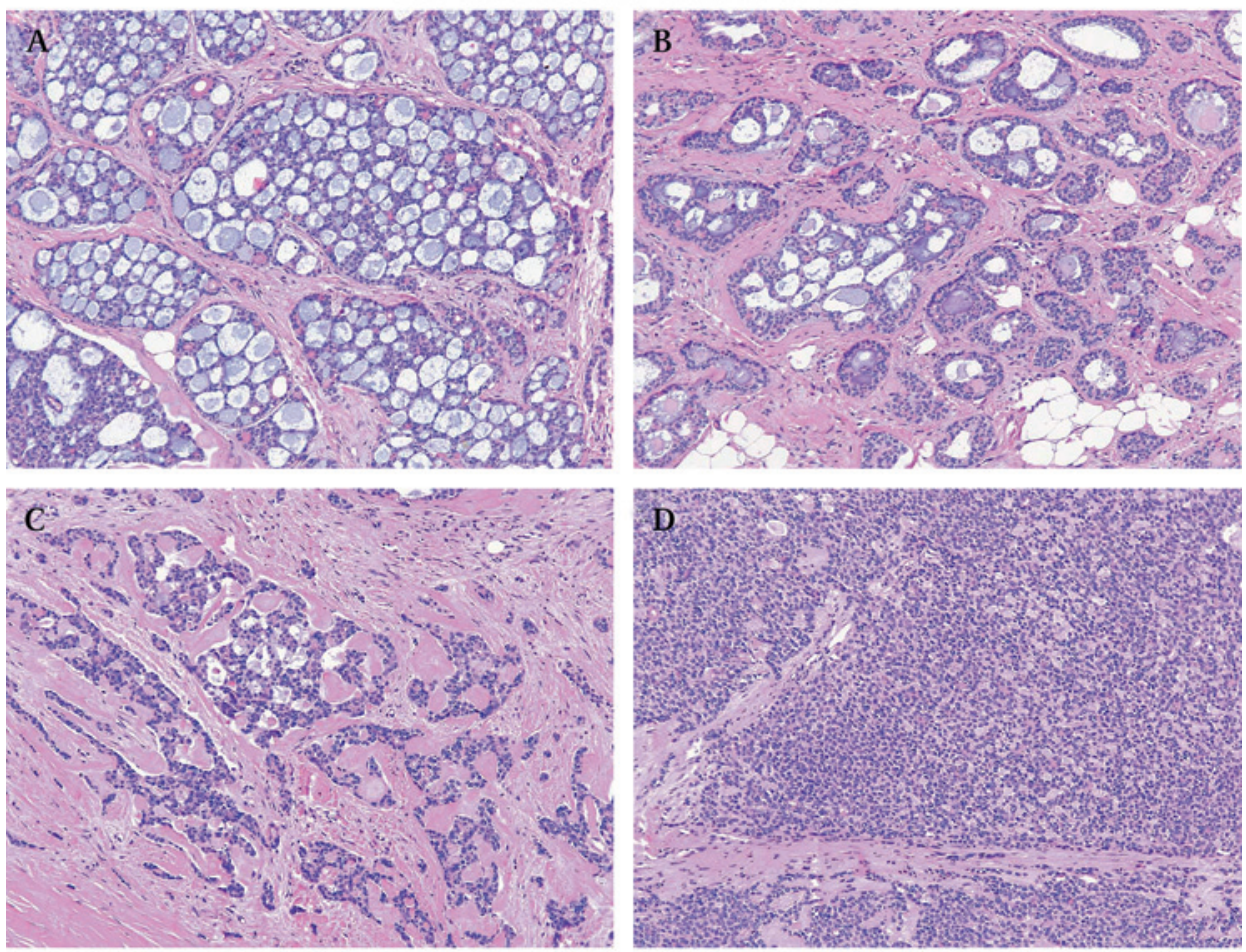

HISTOLOGICAL GRADE
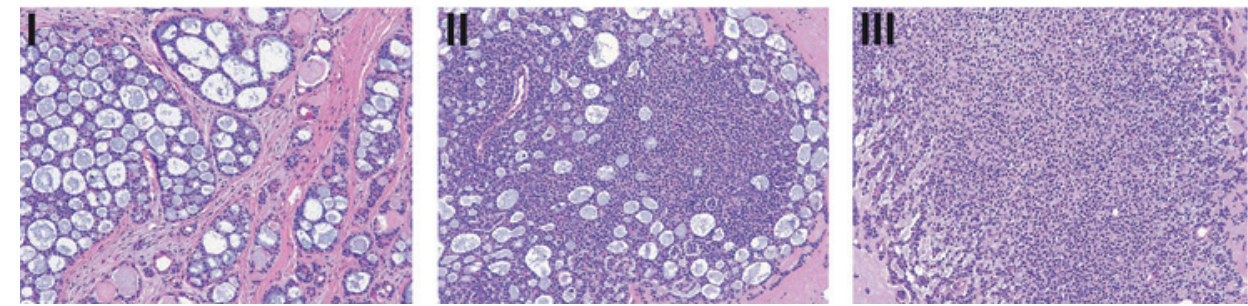

\section{ADENOID CYSTIC CARCINOMAS OF THE SALIVARY GLANDS Clinical and morphological features}

AdCCs are part of the malignant epithelial tumours of the salivary glands and have been recognised as a specific variant of adenocarcinoma of the salivary and mucous glands since $1853 .{ }^{18}{ }^{19}$ AdCC affects patients preferentially in the fourth to sixth decade of life, with a slight female predominance (about 3:2). ${ }^{1} 17$ The parotid gland, submandibular gland and the palate are most commonly involved, ${ }^{17}$ however minor salivary glands in the oesophagus can also be affected. ${ }^{20}$

Table 1 Detailed immunophenotypical characterisation of the two distinct cell types of adenoid cystic carcinoma

\begin{tabular}{lll}
\hline Marker & $\begin{array}{l}\text { Luminal/ } \\
\text { epithelial }\end{array}$ & $\begin{array}{l}\text { Basal/ } \\
\text { myoepithelial }\end{array}$ \\
\hline Cytokeratin 7 & +++ & - \\
Cytokeratin 14 & - & +++ \\
Cytokeratin 17 & - & +++ \\
Vimentin & - & +++ \\
p63 & - & +++ \\
Maspin & - & ++ \\
Laminin & - & ++ \\
Fibronectin & - & ++ \\
c-KIT(CD117) & $+/+++$ & - \\
CyclinD1 & $+/+++$ & - \\
$\beta$-Catenin nuclear & $<5 \%$ & $<5 \%$ \\
\hline
\end{tabular}

AdCCs account for about $10-15 \%$ of all parotid malignancies, ${ }^{21}$ usually present as a slow-growing swelling, and, because of the propensity for perineural invasion, pain may be present (table 2). ${ }^{124}$ In advanced cases, fixation to skin or deeper tissues can occur. ${ }^{1}$ Owing to its growth pattern, it should be also noted that at time of presentation these tumours have often invaded beyond the clinically apparent borders. ${ }^{25-33}$ AdCC of the salivary gland is a slow-growing but aggressive cancer which is reflected by the good short-term but very poor long-term outcome of patients with this disease. ${ }^{1} 34$ The 5 -year survival is about $60-75 \%$, while the 10 -year survival drops to $30-54 \%$; most patients eventually die of disease after multiple local recurrences and development of distant metastases (distant metastases are more common than regional lymph-node involvement). ${ }^{32} 3536$

Histologically, AdCC of the salivary glands presents variable combinations of the three main growth patterns (ie, cribriform, tubular and solid) in each individual case. The cribriform is the most characteristic and is almost invariably found, at least focally. ${ }^{1}$ Cytologically, the basaloid cells constitute the major cell population, showing mild nuclear pleomorphism and few or no mitoses; in the solid variants these cells usually show a more pleomorphic appearance and mitoses are more commonly found. ${ }^{1}$

Salivary gland AdCCs are graded using a specific three-tier grading system, originally proposed by Szanto et a ${ }^{18}$ in 1984 , which is solely based on the main type of growth pattern present 
Table 2 Salivary gland and breast adenoid cystic carcinomas face to face (based on various references ${ }^{18} 14 \begin{array}{llll}15 & 17 & 22 & 23\end{array}$ )

\begin{tabular}{|c|c|c|}
\hline & AdCC salivary glands & AdCC breast \\
\hline Prevalence & $10-15 \%$ of parotid carcinomas & $0.1-1 \%$ of all breast cancers \\
\hline Clinical presentation & Slow-growing swelling & Mass lesion, occasionally painful \\
\hline Gross findings & $\begin{array}{l}\text { Apparently well defined lesion, however often } \\
\text { invading beyond clinically apparent borders }\end{array}$ & $\begin{array}{l}\text { Well defined lesion, with rounded borders } \\
\text { (although microscopically evident invasion of peri-tumoural } \\
\text { tissues is often found) }\end{array}$ \\
\hline Histological growth pattern & & $\begin{array}{l}\text { variant) } \\
\text { (ar) } \\
\text { cular) }\end{array}$ \\
\hline
\end{tabular}

Perineural invasion

Lymph node metastasis

Distant metastases

Pre-invasive and associated lesions

Associated lesions

Survival at 10 years

Therapeutic approach

\section{Very common}

Common

Common (up to $50 \%$ of the patients)

NA

NA

$30-54 \%$

Radical surgery for local disease

Cisplatin usually employed with response rates of $\sim 30 \%$

\section{Rarely found \\ Rare}

Rare, mainly visceral organs involved

MGA, 'atypical' MGA

In situ and invasive carcinomas, tubular adenosis, microglandular adenosis

$>90 \%$

Surgical excision

AdCC, adenoid cystic carcinoma; MGA, microglandular adenosis; NA, not applicable.

in the tumour. Grade 1 AdCCs are well differentiated and composed of tubular and cribriform patterns without solid components; grade 2 AdCCs are characterised by a pure cribriform pattern or mixed with less than $30 \%$ of solid areas; and grade 3 AdCCs are tumours with marked predominance of the solid pattern. ${ }^{18}$ This histological grading system has been shown to be associated with prognosis in retrospective studies. ${ }^{1} 183738$

Recent studies have reported that some low-grade salivary gland carcinomas, including AdCC, can undergo 'dedifferentiation'. ${ }^{39-41}$ This histological variant would show two components, a conventional low-grade AdCC and a high-grade 'dedifferentiated' carcinoma, which can be either undifferentiated carcinoma or poorly differentiated adenocarcinoma. Dedifferentiation is a well recognised phenomenon in bone and soft tissue tumour pathology ${ }^{42}$ and is generally associated with a poor prognosis. In AdCCs it is an extremely rare event (11 cases reported to date), whose clinical behaviour and molecular characteristics are still not entirely understood, ${ }^{43}$ even though recent data seem to support a more aggressive clinical behaviour of dedifferentiated AdCCs. ${ }^{43}$

\section{Molecular features}

The defining molecular feature of AdCCs of the salivary glands and breast appears to be the presence of a recurrent chromosomal translocation $\mathrm{t}(6 ; 9)$ (q22-23; $23-24)$, which generates a fusion transcript involving the genes $M Y B$ and NFIB. ${ }^{9}$ This translocation is described in detail below.

AdCCs of the salivary glands have a stable genome. ${ }^{44}$ TP53 mutations ${ }^{45}$ or p53 nuclear expression have been reported, ${ }^{46-48}$ but in small studies and with discrepant results (see table 3). ${ }^{45} 46$ The presence of aneuploidy appears to be less common in the cribriform variant $(16 \%)$ than in the solid lesions $(67 \%$, table 3$) .{ }^{53}$ Interestingly, a TP53 point mutation and p53 expression have been demonstrated in the dedifferentiated component of two dedifferentiated AdCCs, together with HER2 overexpression and a high proliferation index. ${ }^{43}$

Loss of heterozygosis (LOH), comparative genomic hybridisation $(\mathrm{CGH})$ and microarray-based $\mathrm{CGH}$ studies show conflicting results. Cytogenetic analysis of AdCCs of salivary glands showed deletions of $6 \mathrm{q}$ and $12 \mathrm{q}$ as well as rearrangements involving chromosomes $6 \mathrm{q}$ and $9 \mathrm{p} .{ }^{65}$ Recently, high-resolution $\mathrm{CGH}$ analysis showed that bronchial and salivary AdCCs harbour low levels of genetic instability with few copy number alterations or high-level amplifications. Recurrent gains included $7 \mathrm{p} 15.2,17 \mathrm{q} 21-25$ and 22q11-13, and recurrent losses included $1 \mathrm{p} 35,6 \mathrm{q} 22-25,8 \mathrm{q} 12-13,9 \mathrm{p} 21,12 \mathrm{q} 12-13$ and $17 \mathrm{p} 11-13^{61}$ In addition, Rao et al have recently shown that deletion of 1p32-p36 holds prognostic significance in these lesions. ${ }^{64}$ Given the rather pervasive presence of recurrent regions of deletions, some have studied the possible involvement of tumour suppressor genes: the minimal region of deletions on chromosome $9 \mathrm{p}$ contains CDKN2A and CDKN2B; other possible candidate tumour suppressor genes map to $6 \mathrm{q}^{75}$ and $12 \mathrm{q}$. $^{76}$

Gene amplifications have been investigated, however studies have yielded conflicting results. The majority of studies where gene amplifications were investigated using fluorescence in situ hybridisation (FISH) or CGH have reported a low prevalence of gene amplifications. The only report that identified frequent amplification of ERBB1, CCND1 and PIK3CA (67\%, 46\% and $38 \%$, respectively) in AdCCs relied on a PCR-based method, ${ }^{62}$ which is known to be prone to artefacts when formalin fixed paraffin embedded (FFPE) samples are analysed. Bernheim et al ${ }^{61}$ and Greer et al ${ }^{63}$ have recently identified amplifications of $M D M 2$ (12q15), CCND1 (11q13.3) and CTTN (11q13.3) using FISH (table 3 ); it should be noted, however, that these amplifications affected less than $5 \%$ of cases. On the other hand, CCND1 overexpression seems to be more pervasive than CCND1 amplification, as it is found in up to $90 \%$ of cases. ${ }^{63}$

Apart from the recurrent chromosomal translocation described above, additional translocations have been found in single cases of AdCCs (see table 3) ${ }^{555759}$; however neither the genes involved in these translocations nor their recurrence frequency have been determined.

Two studies have analysed the gene expression profiles of AdCC in salivary glands as compared to normal salivary gland tissues and an AdCC cell line (ACC3): unsupervised hierarchical cluster analysis showed AdCCs separated in three different groups, and interestingly, these groups were not correlated with histological grade. ${ }^{67}$ Overexpression of several genes encoding transcription factors was demonstrated, ${ }^{67}$ and among them, SOX 4 was found to be up-regulated in both studies. ${ }^{66} 67$ Patel et al showed that genes associated with morphogenesis, neurogenesis, proliferation, apoptosis, a group of genes encoding extracellular matrix proteins and basement membrane components seem to characterise AdCCs. In addition, Frierson et al ${ }^{67}$ found epsilon and frizzled-7, both members of the $\mathrm{Wnt} / \beta$-catenin signalling 
Table 3 Summary of genomic features reported in adenoid cystic carcinomas of breast and salivary glands

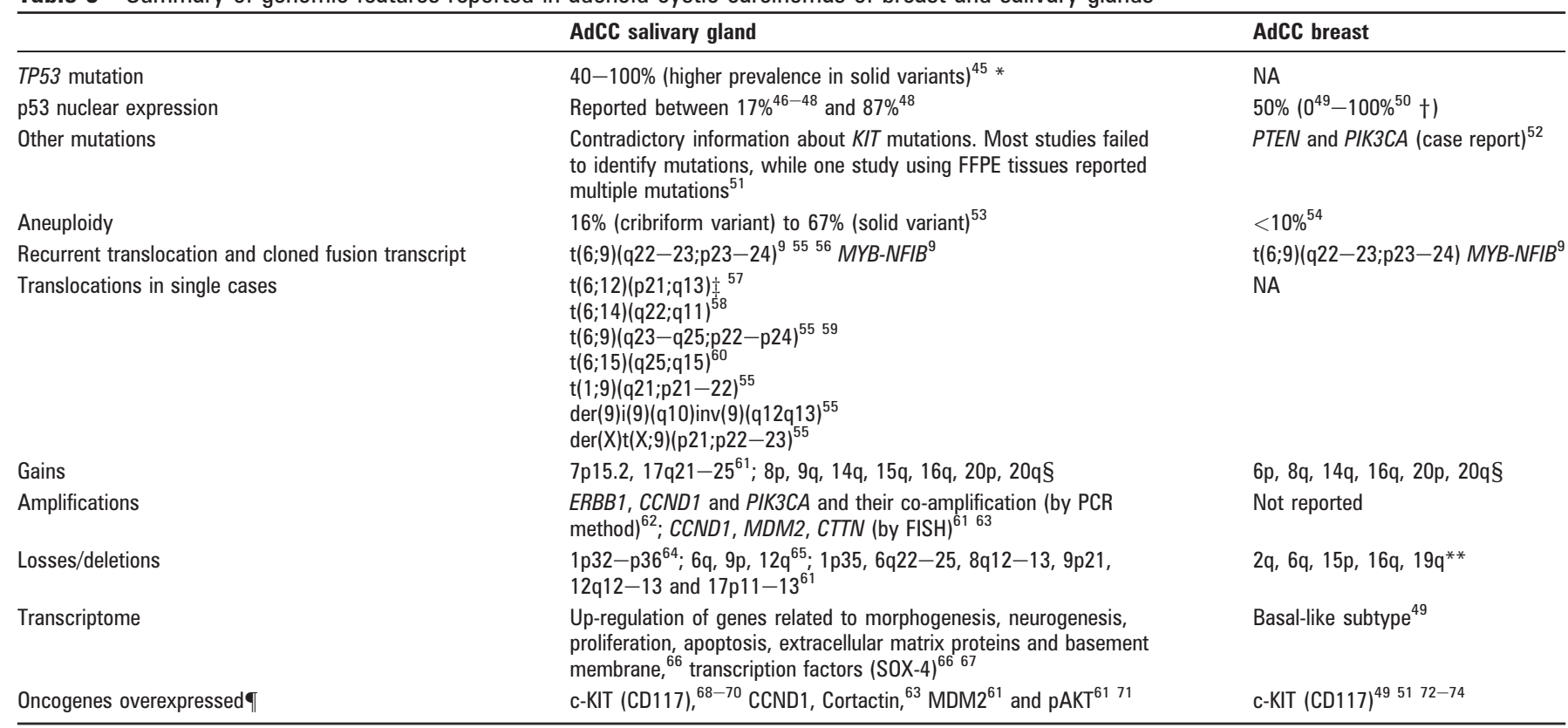

*Performed with nucleic acids extracted from FFPE tissues.

†p53 immunohistochemical analysis using pressure cooking antigen retrieval.

†Translocation described in one case of AdCC and one case of polymorphous low-grade adenocarcinomas.

§Fulford, Reis-Filho and Lakhani (unpublished observations).

$\checkmark$ As defined by immunohistochemistry.

AdCC, adenoid cystic carcinoma; IHC, immunohistochemistry; NA, not applicable.

pathway, to be up-regulated in AdCCs compared to 175 other carcinomas from 10 anatomical sites.

\section{ADENOID CYSTIC CARCINOMAS OF THE BREAST Clinical, morphological and immunohistochemical features}

After Geschickter's description of 'adenocystic basal cell carcinoma' of the breast, ${ }^{8}$ three adenocystic basal cell carcinomas were reported by Foote and Stewart in $1946,{ }^{3}$ but it was only two decades afterwards that Galloway ${ }^{77}$ at the Mayo clinic described the first series of mammary adenoid cystic carcinomas. ${ }^{8}$ Since then several groups have described AdCCs of the breast; however due to the relative rarity of this tumour type, most studies are in the form of case reports or small cohorts.

The existence of AdCC in the breast has been questioned, given its morphological similarity with cribriform carcinoma ${ }^{22} 78$; however, immunohistochemical and ultrastructural studies have eventually proven the existence of true AdCC in the breast (see below), which is now recognised as one of 17 histological special types of breast cancer by the World Health Organization. ${ }^{15} 21-2379$ AdCCs account for $0.1-1 \%$ of all breast cancers ${ }^{815} 23$; they are usually diagnosed in adult female patients as unilateral painful masses. ${ }^{81523}$ This associated pain has been suggested to be due to the contractile myoepithelial component of these tumours, as perineural invasion is not commonly seen in these lesions (table 2). ${ }^{815}$ All quadrants seem to be affected, with a particular trend for the peri-areolar region. ${ }^{8}$ The most striking feature of AdCCs of the breast, which is in stark contrast with AdCCs of salivary glands, is the excellent long-term prognosis (table 2): a $90-100 \% 10$-year survival rate is reported, and lymph-node metastases are rare, as well as distant metastases, which affect mainly visceral organs. ${ }^{15} 54$

AdCC can be found in conjunction with other breast lesions, including ipsilateral and controlateral in situ and invasive carcinomas. ${ }^{15}$ In addition, recent studies have noted an association between AdCC and microglandular adenosis (MGA), ${ }^{80-83}$ and some authors have suggested that AdCC may develop in a background of and in continuity with MGA. Following this hypothesis there would be a spectrum of lesions with a trend of progression, encompassing MGA, 'atypical' MGA (also known as 'in situ AdCC') and invasive AdCC. ${ }^{80}$ An association between AdCC and tubular adenosis (TA) has also been reported in one study, but the molecular analysis performed on these two lesions failed to provide evidence of molecular evolution from TA to AdCC. ${ }^{14}$

The variety of growth patterns described for AdCCs of the salivary glands is also found when this tumour arises in the breast: the classic cribriform pattern, as well as the glandular, trabecular and solid variants. ${ }^{8}$ A sebaceous differentiation is found in up to $14 \%$ of cases, and foci of adenosquamous differentiation may also be encountered. ${ }^{8} 84$

In a way akin to salivary gland AdCC, breast AdCCs are graded according to the proportion of solid growth: cases with either cribriform or glandular pattern are considered low grade/ G1 tumours, cases with $<30 \%$ of solid elements are labelled as G2, whereas cases showing $>30 \%$ of solid growth are classified as high grade/G3 tumours (figure 1). ${ }^{8} 13$ Ro et al ${ }^{13}$ reported this grading system to be clinically meaningful, as in their series, tumours with solid components (G2 and G3 cases) were more likely to develop recurrences; in addition, in the same cohort, the only patient who experienced metastases was affected by a highgrade tumour. It should be noted however that histological grade defined by this system was not associated with outcome in two other studies. ${ }^{85} 86$

Other authors ${ }^{72}$ have suggested the proliferative indices to be of some relevance as they showed greater values in high-grade when compared with low-grade lesions; however proliferative activity was not found to be significantly related to prognosis. ${ }^{85}$

Phenotypically, AdCCs are described as hormone receptor negative carcinomas (table 4). In the series of 18 cases analysed by Azoulay et al, ${ }^{73}$ neither oestrogen receptor (ER) nor progesterone receptor (PR) expression was identified. Similar findings have been reported in other independent series (table 4). ${ }^{49} 5094$ 
One study ${ }^{72}$ reported that $15 \%$ and $10 \%$ of cases were positive for ER and PR, respectively (table 4). In contrast, Arpino et a ${ }^{54}$ demonstrated the presence of ER and PR expression in up to $46 \%$ $(13 / 28)$ and $36 \%(10 / 28)$ of cases, respectively (table 4$)$. Although this cohort represents one of the largest series of AdCCs reported to date $(n=28)$, it should be noted that the cases were collected from different institutions and did not undergo a central review; hence, it cannot be formally ruled out that a substantial number of cases included in that study were cribriform carcinomas, which are usually ER and PR positive. In addition, it should be noted that dextran-coated charcoal assay, ${ }^{87}$ instead of immunohistochemistry, was used to assess positivity for ER and PR and only 85\% agreement between the two techniques is reported. ${ }^{88}$ The use of the dextran-coated charcoal assay for ER and PR assessment of AdCCs is particularly problematic, given that normal breast lobules and ducts are often entrapped within the bulk of AdCCs, which may lead to false positive results.

\section{Molecular features}

In a way akin to salivary gland AdCCs, breast AdCCs consistently display the recurrent chromosomal translocation $t(6 ; 9)$ (q22-23;p23-24), which generates fusion transcripts involving the genes $M Y B$ and NFIB. ${ }^{9}$ This translocation is described in detail below.

Although microarray-based gene expression profiling has been extensively applied to the study of breast cancer, most of these analyses ignored the histological special types of breast cancer (reviewed in Weigelt et $a l^{89}$ and Weigelt and Reis-Filho ${ }^{90}$ ), and there is paucity on the transcriptomic features of AdCCs. The molecular subtypes of breast cancer (ie, basal-like, HER2, luminal A, luminal B and normal breast-like), which provide a widely used working model for a breast cancer molecular taxonomy, have been identified by microarray analysis of only the most common types, invasive ductal and invasive lobular carcinomas. $^{91-93}$ This molecular classification was shown to be of prognostic significance, with tumours of luminal A subtype being associated with the best outcome, and tumours of basallike or HER2 subtype with the worst outcome. ${ }^{91} 94$

To date, only one study has formally investigated the transcriptome of breast AdCCs. Using microarray-based gene expression profiling, Weigelt et al ${ }^{49}$ analysed a series of 113 tumours from 11 special histological types of breast cancer, including four AdCCs. Unsupervised hierarchical cluster analysis showed that AdCCs clustered together with metaplastic and medullary carcinomas, whose similar gene expression patterns were also reflected at the immunohistochemical level (triple negative phenotype; ie, lack of ER, PR and HER2; low levels of Ck19, AR and Ck8/18; high levels of CD117, vimentin, S100, Ck14 and Ck5/6 expression). In addition, molecular subtype analysis using a single sample predictor (ie, centroids) showed that two AdCCs were of basal-like and two AdCCs of normal breast-like phenotype, a molecular subtype which is currently considered to be an artefact of sample representation (ie, high content of normal tissue contamination). ${ }^{95}$ Indeed, molecular subtype assignment by hierarchical clustering showed that AdCCs consistently displayed a basal-like phenotype, as did medullary and metaplastic carcinomas. These results support earlier immunohistochemical observations by Azoulay et al $^{73}$ that breast AdCCs lack expression of ER, PR and HER2 (ie, triple negative phenotype) and express basal cytokeratins $(\mathrm{Ck} 5 / 6)$. These observations illustrate the heterogeneity of basal-like breast cancers and emphasise that triple negative and basal-like breast cancer is not a single entity, but rather a spectrum of lesions. Although the majority of triple negative and basal-like breast cancers are high grade cancers (ie, medullary carcinomas, grade 3 invasive ductal carcinomas of no special type (IDC-NSTs), metaplastic carcinomas and apocrine carcinomas $^{49} 73$ 96-99$)$, there is a subgroup of low grade tumours with indolent clinical behaviour that also display a triple negative and basal-like phenotype (ie, AdCCs and secretory carcinomas). Contrary to high grade triple negative and basallike breast cancers, ${ }^{100}$ which have been shown to harbour TP53 mutations in $>80 \%$ of cases, ${ }^{101}$ two studies have reported that p53 nuclear expression is either absent ${ }^{49}$ or seen in $25 \%$ of $\mathrm{AdCCs}^{102}$; on the other hand, one study reported p53 expression in 6/6 AdCCs analysed. ${ }^{50}$ Furthermore, AdCCs do not appear to be more prevalent in BRCA1 germ-line mutation carriers.

There is not only a paucity of data on transcriptomic but also on the genomic features of AdCC of the breast. Cytogenetic analyses of a few cases showed 46,XX,t(4;4)(q21;q35),t(5;11) (q13;q21), 46,XX,+1,der(1;16) (q10;p10) ${ }^{103}$ and 46,XX,inv(9). ${ }^{65}$ Aneuploidy is reported in less than $10 \%$ of cases. ${ }^{54}$

In a recent case report of a 76-year-old woman affected by a breast AdCC with a kidney metastasis, molecular genetic analysis of the primary and metastatic tumour revealed both a PTEN and a PIK3CA mutation. ${ }^{52}$ These findings led the authors to speculate that PTEN and PIK3CA mutations may be responsible for the unusually aggressive course of this particular AdCC and suggested identified novel molecular targets for therapeutic intervention. Further studies on larger cohorts are needed to confirm the prevalence of these mutations and their biological role in AdCC.

The limited molecular features of breast AdCC available suggest that these tumours have a relatively stable genome and are characterised by a recurrent chromosomal translocation involving $M Y B$ and NFIB. Although AdCCs are of triple negative and basal-like phenotype, a diagnosis of breast AdCC should not necessarily prompt the use of systemic chemotherapy, given the excellent prognosis of patients with this tumour type.

Table 4 Overview of data reported on the expression of prognostic and predictive factors, p63, basal cytokeratins and c-KIT in adenoid cystic carcinoma of the breast

\begin{tabular}{|c|c|c|c|c|c|c|}
\hline & $\begin{array}{l}\text { Trendell-Smith et al, } \\
1999^{50}(\mathrm{~N}=6)\end{array}$ & $\begin{array}{l}\text { Arpino et al, } 2002^{54} \\
(\mathrm{~N}=28)\end{array}$ & $\begin{array}{l}\text { Mastropasqua } \\
\text { et al, } 2005^{72}(\mathrm{~N}=20)\end{array}$ & $\begin{array}{l}\text { Crisi et al, } 2005^{74} \\
(\mathrm{~N}=6)\end{array}$ & $\begin{array}{l}\text { Azoulay et al, } \\
2005^{73}(\mathrm{~N}=18)\end{array}$ & $\begin{array}{l}\text { Weigelt et al, } \\
2008^{49}(\mathrm{~N}=4)\end{array}$ \\
\hline ER & $0 \%$ & $46 \%$ & $15 \%$ & $0 \%$ & $0 \%$ & $0 \%$ \\
\hline PR & $0 \%$ & $36 \%$ & $10 \%$ & $0 \%$ & $0 \%$ & $0 \%$ \\
\hline p63 & NA & NA & $85 \%$ & NA & $100 \%$ & $50 \%$ \\
\hline Cytokeratin 5/6 & NA & NA & NA & NA & $100 \%$ & $75 \%$ \\
\hline c-KIT (CD117) & NA & NA & $95 \%$ & $100 \%$ & $100 \%$ & $100 \%$ \\
\hline
\end{tabular}

ER, oestrogen receptor; NA, not available; PR, progesterone receptor. 


\section{MOLECULAR COMPARATIVE PATHOLOGY AND THERAPEUTIC INSIGHTS FOR ADCC: FACTS AND ARTEFACTS C-KIT: therapeutic target or unjustified hope?}

The gene KIT maps to 4q11-q12 and encodes c-KIT (CD117), a type III transmembrane tyrosine kinase receptor, which is activated by mutations in gastrointestinal stromal tumours and melanomas. Tumours harbouring KIT mutation but not overexpression of wild-type c-KIT can be targeted by the small molecule inhibitor imatinib mesylate (Gleevec, Novartis) and sorafenib (Nexavar, Bayer).

c-KIT has been shown to be expressed in up to $100 \%$ of AdCCs of the breast ${ }^{49} 5172-74$ and in $80-100 \%$ of AdCCs of the salivary glands arising from the head and neck. ${ }^{68-70}$ These observations have prompted several groups to investigate whether imatinib would be a valid therapeutic option for those lesions arising in salivary glands. Bold claims were made in 2005 in a study by Faivre et al, ${ }^{104}$ showing a remarkable response to imatinib treatment in a patient affected by AdCC of salivary glands. These data could, however, never be confirmed by subsequent clinical studies which failed to identify objective clinical responses in patients with AdCC treated with imatinib. ${ }^{69} 105106$ In contrast with Faivre et al, ${ }^{104}$ there are descriptions of progression of metastatic AdCC under treatment with imatinib (table 5). ${ }^{105}$ These disappointing results should not come as a surprise, given that activating KIT mutations, the determinant for response to imatinib treatment, ${ }^{109}$ have been repeatedly reported to be vanishingly rare in these cancers. ${ }^{69} 70104105$ Last year, however, Vila et al ${ }^{51}$ demonstrated the presence of multiple KIT mutations in AdCCs and even multiple mutations in single cases. Owing to the small number of tumours analysed (extraction of DNA was successful in only $8 / 14$ cases) and, most importantly, to the type of sample subjected to mutation analysis (ie, FFPE samples), these findings needs to be confirmed in larger cohorts using optimally processed samples (ie, fresh/frozen samples).

Taken together, the balance of evidence available to date suggest that c-KIT may not constitute a potential novel therapeutic target for AdCC.

\section{A translocation in common}

Persson et al ${ }^{9}$ have recently shown that breast, salivary, lachrymal and ceruminal gland AdCCs harbour a recurrent specific translocation $\mathrm{t}(6 ; 9)$ (q22-23;p23-24). This genetic alteration had already been described more than 10 years ago, by the same group, as characteristic of salivary glands. However, the fusion gene partners in this translocation have only now been identified: the oncogene $M Y B$ on chromosome $6 \mathrm{q} 22-\mathrm{q} 23$ and the transcription factor NFIB on chromosome 9p23-p24. ${ }^{9}$ MYB maps to chromosome $6 \mathrm{q} 22-\mathrm{q} 23$ and encodes a transcription factor with an N-terminal DNA binding domain, a centrally located transcription activation domain, and a C-terminal negative regulatory domain, which plays a pivotal role in the control of cell proliferation, apoptosis and differentiation. It is highly expressed in immature, proliferating cells, fetal salivary gland; however it is down-regulated as cells become more differentiated. ${ }^{9}$ In the $t(6 ; 9)(q 22-q 23 ; p 23-p 24)$, the exon 14 of $M Y B$ is fused to the last coding exons of NFIB, most often due to breakpoints in $M Y B$ intron 14 and in NFIB intron 8. This translocation was shown to produce distinct types of fusion transcripts due to splice variations of the $M Y B$ gene. The common denominator of these genetic aberrations, however, was a deletion of exon 15 of MYB and its 3 '-UTR, which contains several highly conserved target sites for miR-15a/16 and miR-150 microRNAs. In normal and cancer cells, these miRNAs have been shown to down-regulate the expression of MYB. Consistent with this hypothesis, transfection of leukaemic cells with premiR-15a/ 16 and premiR-150 resulted in a significant down-regulation of MYB mRNA expression, whereas transfection of ACC cells did not alter the expression levels of MYB significantly. ${ }^{9}$

Despite the limited number of samples analysed so far, ${ }^{9}$ this is the first fusion transcript identified in AdCCs. Although the use of split apart probes for the identification of this translocation are unlikely to be used in diagnostic practice, due to the characteristic histological features of AdCC, one can envisage that these probes may help reclassify some tumours with features overlapping with those of AdCC or mixed salivary gland tumours.

Table 5 Summary of clinical trials where imatinib mesylate (Gleevec, Novartis) was tested in patients with adenoid cystic carcinoma of salivary glands

\begin{tabular}{|c|c|c|c|c|c|c|}
\hline Type of trial & Enrolled patients & $\begin{array}{l}\text { c-KIT } \\
\text { expression } \\
\text { by IHC }\end{array}$ & $\begin{array}{l}\text { KIT or PDFRA } \\
\text { mutations }\end{array}$ & Imatinib dose & Results & Reference \\
\hline $\begin{array}{l}\text { Multicentre single arm, two } \\
\text { stage phase II clinical trial }\end{array}$ & $\begin{array}{l}\text { Patients }(\mathrm{N}=16) \text { with } \\
\text { unresectable or metastatic } \\
\text { AdCC }\end{array}$ & Present & NP & $400 \mathrm{mg} \times 2$ daily & $\begin{array}{l}\text { No evidence of objective } \\
\text { response in } 15 \text { assessable } \\
\text { patients. Early termination } \\
\text { after completion of the first } \\
\text { stage }\end{array}$ & Hotte et al, $2005^{107}$ \\
\hline $\begin{array}{l}\text { Phase II study with } \\
\text { combination of imatinib } \\
\text { mesylate and cisplatin }\end{array}$ & $\mathrm{N}=14$ & Present & NP & $\begin{array}{l}800 \mathrm{mg} \text { as single agent; } \\
400 \mathrm{mg} \text { in combination } \\
\text { with cisplatin } 80 \mathrm{mg} / \mathrm{m}^{2}\end{array}$ & $\begin{array}{l}\text { Of the } 12 \text { assessable } \\
\text { patients, } 2 \text { developed DP } \\
\text { with imatinib as single agent } \\
\text { and left the study; } 1 \text { had } \\
\text { a documented PR; } 4 \text { had } \\
\text { reduction in tumour size; the } \\
\text { others showed SD (but short } \\
\text { follow-up) }\end{array}$ & Slevin et al, $2004^{108}$ \\
\hline Pilot study & $\begin{array}{l}\text { Patients }(N=5) \text { with } \\
\text { metastatic } A d C C\end{array}$ & Present & No & $400 \mathrm{mg} \times 2$ daily & $\mathrm{DP}$ in $2 / 5 ; \mathrm{DOD}$ in $3 / 5$ & Lin et al, $2005^{105}$ \\
\hline
\end{tabular}




\section{Take-home messages}

- Adenoid cystic carcinomas (AdCCs) in salivary glands represent a very aggressive type of lesion, whereas breast adenoid cystic carcinoma shows a very good clinical behaviour, with an excellent 10 -year prognosis.

- Breast AdCCs have a triple negative and basal-like phenotype; however they have a good long-term outcome.

- Breast and salivary gland AdCCs harbour the $t(6 ; 9)(q 22-q 24$; p21-p23) recurrent translocation, involving the MYB and NFIB genes.

- At the present time, no specific targeted therapy is available for AdCC of either breast or salivary glands.

This fusion gene may provide new therapeutic avenues for the management of advanced AdCC; however, one must remember that targeting transcription factors is by no means a trivial task. Further functional studies investigating in greater depth the biological consequences of the $M Y B$ gain of function due to the $M Y B-N F I B$ fusion are eagerly awaited. Importantly, gene silencing experiments to demonstrate that $M Y B$ expression is selectively required for the survival of cancer cells with genetically activated $M Y B$ have yet to be performed.

\section{CONCLUSIONS}

As salivary and mammary glands are exocrine glands both showing a tubulo-acinar architecture, the remarkable similar morphological features observed in tumours arising in these two glandular structures should perhaps not come as a surprise. ${ }^{110}$ A good example is offered by salivary duct carcinoma, a lesion that, at the morphological level, is remarkably similar to invasive ductal carcinomas of the breast, ${ }^{92}$ and that can be categorised in the same molecular subtypes as those identified in invasive ductal breast carcinomas, namely luminal, HER2 and basal subtypes. ${ }^{111}$

AdCCs constitute an even better example of the similarities between the tumours affecting these sites. AdCCs of breast and salivary glands share a common pattern of growth, harbour an identical recurrent fusion gene (MYB-NFIB), and similar patterns of numerical chromosomal alterations. Surprisingly, however, despite these similarities, the behaviour of salivary gland and breast AdCCs differs: while salivary gland lesions have an aggressive behaviour and often metastasise, breast lesions have a much more indolent clinical course.

Although great strides have been made in the characterisation of these tumours, several questions remain unanswered. Do AdCCs constitute a tumour type with pluripotent patterns of evolution? And if so, what are the determinants of the distinct evolution/clinical behaviour? If overexpression of $M Y B$ and its target genes is the common denominator in the genesis of AdCCs regardless of the site of origin, what then makes their behaviour differ in salivary gland and breast? It would be plausible that different tumour-microenvironment interactions may account for the different metastatic proclivity of breast and salivary gland AdCCs; alternatively, it could be that the MYB-NFIB translocation may have similar impacts on the morphology of the tumour in different sites, but different effects on the metastatic ability dependent on the target epithelial cell (ie, cell of origin). With the advent of massively parallel sequencing and the opportunity to characterise the genome and transcriptome from these cancers, new opportunities to define the molecular determinants of the behaviour of these fascinating lesions will emerge. 112113
Acknowledgements The authors are grateful to Dr Riccardo Arisio (Sant'Anna Hospital, Turin) for the courtesy of the breast AdCC case illustrated in (figure 1).

Funding This study was funded by Breakthrough Breast Cancer and Ricerca Sanitaria Finalizzata Regione Piemonte 2009. BW is funded by a Cancer Research UK fellowship. NHS funding to the NIHR Biomedical Research Centre is also acknowledged.

\section{Competing interests None.}

Provenance and peer review Commissioned; not externally peer reviewed.

\section{REFERENCES}

1. Cheuk W, Chan J. Salivary gland tumors. In: Fletcher C, ed. Diagnostic histopathology of tumors. New York: Churchill Livingstone Elsevier, 2007: 280-4.

2. Gray HR, Helwig EB. Epithelioma adenoides cysticum and solitary trichoepithelioma. Arch Dermatol 1963;87:102-14.

3. Hajdu SI, Huvos AG, Goodner JT, et al. Carcinoma of the trachea. Clinicopathologic study of 41 cases. Cancer 1970;25:1448-56.

4. Huvos AG, Strong EW. Epithelial tumors of the lacrimal gland. Lab Invest 1973;28:386.

5. Lassaletta L, Patron M, Oloriz J, et al. Avoiding misdiagnosis in ceruminous gland tumours. Auris Nasus Larynx 2003;30:287-90.

6. Nelms DC, Luna MA. Primary adenocystic carcinoma (cylindromatous carcinoma) of the esophagus. Cancer 1972:29:440-3.

7. Weltzer S. Adenoid cystic carcinoma of the breast. Am Surg 1970;36:271.

8. Rosen PP. Adenoid cystic carcinoma. In: Rosen PP, ed. Rosen's breast pathology. Philadelphia: Lippincott Williams and Wilkins, 2009:590-604.

9. Persson M, Andren Y, Mark J, et al. Recurrent fusion of MYB and NFIB transcription factor genes in carcinomas of the breast and head and neck. Proc Natl Acad Sci U S A 2009;106:18740-4.

10. Billroth T. Beobachtungen über Geschwülste der Speicheldrüsen. Virchows Arch Path Anat 1859;17:357-75.

11. Ewing J. Epithelial tumors of the salivary gland, in neoplastic diseases. Philadelphia: WB Saunders, 1919: 780

12. Geschickter CK. Diseases of the breast, in diagnosis, pathology, treatment. Philadelphia: JB Lippincott, 1945: 824.

13. Ro JY, Silva EG, Gallager HS. Adenoid cystic carcinoma of the breast. Hum Pathol 1987;18:1276-81.

14. Da Silva L, Buck L, Simpson PT, et al. Molecular and morphological analysis of adenoid cystic carcinoma of the breast with synchronous tubular adenosis. Virchows Arch 2009;454:107-14.

15. Bennett AK, Mills SE, Wick MR. Salivary-type neoplasms of the breast and lung. Semin Diagn Pathol 2003;20:279-304.

16. Reis-Filho JS, Milanezi F, Silva P, et al. Maspin expression in myoepithelial tumors of the breast. Pathol Res Pract 2001;197:817-21.

17. Ellis GL, Auclair PL. Adenoid cystic carcinoma, in atlas of tumor pathology-tumors of the salivary glands. Washington, DC: Armed Forces Institute of Pathology, 1996: 203-15.

18. Szanto PA, Luna MA, Tortoledo ME, et al. Histologic grading of adenoid cystic carcinoma of the salivary glands. Cancer 1984;54:1062-9.

19. Tauxe WN, Mc DJ, Devine KD. A century of cylindromas. short review and report of 27 adenoid cystic carcinomas arising in the upper respiratory passages. Arch Otolaryngol 1962;75:364-76.

20. De Dosso S, Mazzucchelli L, Ghielmini M, et al. Response to oxaliplatin with cetuximab in minor salivary gland adenoid cystic carcinoma. Tumori 2009;95:378-81.

21. Barnes L, Eveson J, Reichart P, et al. Pathology and genetics of head and neck tumours. In: Kleihues R, Sobin LH, eds. World Health Organization classification of tumours. Lyon: IARC, 2005:221-2.

22. Ellis I0, Pinder S, Lee AHS. Tumors of the breast-adenoid cystic carcinoma. In: Fletcher C, ed. Diagnosti histopathology of tumors. Churchill Livingstone Elsevier, 2007: 953-4.

23. Ellis I0, Schnitt SJ, Sastre-Garau X, et al. Invasive Breast Carcinoma. In: Tavassol FA, Devilee P, eds. World health organization classification of tumours - pathology and genetics, tumours of the breast and female genital organs. Lyon: IARC Press, 2003: 44-5.

24. Friedrich RE, Bleckmann V. Adenoid cystic carcinoma of salivary and lacrimal gland origin: localization, classification, clinical pathological correlation, treatment results and long-term follow-up control in 84 patients. Anticancer Res 2003;23:931-40.

25. Chomette G, Auriol M, Tranbaloc P, et al. Adenoid cystic carcinoma of minor salivary glands. Analysis of 86 cases. Clinico-pathological, histoenzymological and ultrastructural studies. Virchows Arch A Pathol Anat Histol 1982;395:289-301.

26. Conley J, Dingman DL. Adenoid cystic carcinoma in the head and neck (cylindroma). Arch Otolaryngol 1974;100:81-90

27. Eby LS, Johnson DS, Baker HW. Adenoid cystic carcinoma of the head and neck. Cancer 1972;29:1160-8.

28. Eneroth CM, Zajicek J. Aspiration biopsy of salivary gland tumors. IV. Morphologic studies on smears and histologic sections from 45 cases of adenoid cystic carcinoma. Acta Cytol 1969;13:59-63.

29. Leafstedt SW, Gaeta JF, Sako K, et al. Adenoid cystic carcinoma of major and minor salivary glands. Am J Surg 1971;122:756-62.

30. Matsuba HM, Simpson JR, Mauney M, et al. Adenoid cystic salivary gland carcinoma: a clinicopathologic correlation. Head Neck Surg 1986;8:200-4. 
31. Nascimento AG, Amaral AL, Prado LA, et al. Adenoid cystic carcinoma of salivary glands. A study of 61 cases with clinicopathologic correlation. Cancer 1986;57:312-19

32. Perzin KH, Gullane P, Clairmont AC. Adenoid cystic carcinomas arising in salivary glands: a correlation of histologic features and clinical course. Cancer 1978;42:265-82.

33. Spiro RH, Huvos AG, Strong EW. Adenoid cystic carcinoma of salivary origin a clinicopathologic study of 242 cases. Am J Surg 1974;128:512-20.

34. Wahlberg $\mathbf{P}$, Anderson $\mathrm{H}$, Biorklund $\mathrm{A}$, et al. Carcinoma of the parotid and submandibular glands-a study of survival in 2465 patients. Oral Oncol 2002;38:706-13.

35. Hamper K, Lazar F, Dietel M, et al. Prognostic factors for adenoid cystic carcinoma of the head and neck: a retrospective evaluation of 96 cases. J Oral Pathol Med 1990;19:101-7.

36. Chilla R, Schroth R, Eysholdt U, et al. Adenoid cystic carcinoma of the head and neck. Controllable and uncontrollable factors in treatment and prognosis. ORL $J$ Otorhinolaryngol Relat Spec 1980;42:346-67.

37. Batsakis JG, el-Naggar AK. Myoepithelium in salivary and mammary neoplasms is host-friendly. Adv Anat Pathol 1999:6:218-26.

38. Batsakis JG, Luna MA, el-Naggar A. Histopathologic grading of salivary gland neoplasms: III. Adenoid cystic carcinomas. Ann Otol Rhinol Laryngol 1990;99:1007-9.

39. Chau Y, Hongyo T, Aozasa K, et al. Dedifferentiation of adenoid cystic carcinoma: report of a case implicating p53 gene mutation. Hum Pathol 2001;32:1403-7.

40. Cheuk W, Chan JK, Ngan RK. Dedifferentiation in adenoid cystic carcinoma of salivary gland: an uncommon complication associated with an accelerated clinical course. Am J Surg Pathol 1999;23:465-72.

41. Moles MA, Avila IR, Archilla AR. Dedifferentiation occurring in adenoid cystic carcinoma of the tongue. Oral Surg Oral Med Oral Pathol Oral Radiol Endod 1999;88:177-80.

42. Meis JM. "Dedifferentiation" in bone and soft-tissue tumors. A histological indicator of tumor progression. Pathol Annu 1991:26(Pt 1):37-62.

43. Nagao T, Gaffey TA, Serizawa H, et al. Dedifferentiated adenoid cystic carcinoma: a clinicopathologic study of 6 cases. Mod Pathol 2003;16:1265-72

44. Yu Y, Baras AS, Shirasuna K, et al. Concurrent loss of heterozygosity and copy number analysis in adenoid cystic carcinoma by SNP genotyping arrays. Lab Invest 2007;87:430-9.

45. Yamamoto $\mathbf{Y}$, Wistuba II, Kishimoto $Y$, et al. DNA analysis at p53 locus in adenoid cystic carcinoma: comparison of molecular study and p53 immunostaining. Pathol Int 1998:48:273-80

46. Kiyoshima T, Shima K, Kobayashi I, et al. Expression of p53 tumor suppressor gene in adenoid cystic and mucoepidermoid carcinomas of the salivary glands. Oral Oncol 2001:37:315-22.

47. Preisegger KH, Beham A, Kopp S, et al. Prognostic impact of molecular analyses in adenoid cystic carcinomas of the salivary gland. Onkologie 2001;24:273-7.

48. Zhu OR, White FH, Tipoe GL. p53 oncoprotein accumulation in adenoid cystic carcinoma of parotid and palatine salivary glands. Pathology 1997;29:154-8.

49. Weigelt B, Horlings HM, Kreike B, et al. Refinement of breast cancer classification by molecular characterization of histological special types. J Pathol 2008; 216:141-50.

50. Trendell-Smith NJ, Peston D, Shousha S. Adenoid cystic carcinoma of the breast: a tumour commonly devoid of oestrogen receptors and related proteins. Histopathology 1999;35:241-8.

51. Vila L, Liu H, Al-Quran SZ, et al. Identification of c-kit gene mutations in primary adenoid cystic carcinoma of the salivary gland. Mod Pathol 2009;22:1296-302.

52. Vranic S, Bilalovic N, Lee LM, et al. PIK3CA and PTEN mutations in adenoid cystic carcinoma of the breast metastatic to kidney. Hum Pathol 2007;38:1425-31.

53. Enamorado I, Lakhani R, Korkmaz H, et al. Correlation of histopathological variants, cellular DNA content, and clinical outcome in adenoid cystic carcinoma of the salivary glands. Otolaryngol Head Neck Surg 2004;131:646-50.

54. Arpino G, Clark GM, Mohsin S, et al. Adenoid cystic carcinoma of the breast: molecular markers, treatment, and clinical outcome. Cancer 2002:94:2119-27.

55. Nordkvist A, Mark J, Gustafsson H, et al. Non-random chromosome rearrangements in adenoid cystic carcinoma of the salivary glands. Genes Chromosomes Cancer 1994:10:115-21.

56. Jin Y, Mertens F, Limon J, et al. Characteristic karyotypic features in lacrimal and salivary gland carcinomas. Br J Cancer 1994;70:42-7.

57. Martins C, Fonseca I, Roque L, et al. Cytogenetic similarities between two types of salivary gland carcinomas: adenoid cystic carcinoma and polymorphous low-grade adenocarcinoma. Cancer Genet Cytogenet 2001;128:130-6.

58. Bell D, Zhao Y, Rao HP, et al. Translocation $\mathrm{t}(6 ; 14)$ as the sole chromosomal abnormality in adenoid cystic carcinoma of the base of tongue. Head Neck Pathol 2007:1:165-8.

59. Stenman G, Sandros J, Dahlenfors R, et al. 6q-and loss of the $Y$ chromosome-two common deviations in malignant human salivary gland tumors. Cancer Genet Cytogenet 1986;22:283-93.

60. el-Naggar AK, Lovell M, Callender DL, et al. Limited nonrandom chromosomal aberrations in a recurrent adenoid cystic carcinoma of the parotid gland. Cancer Genet Cytogenet 1999;109:66-9.

61. Bernheim A, Toujani S, Saulnier P, et al. High-resolution array comparative genomic hybridization analysis of human bronchial and salivary adenoid cystic carcinoma. Lab Invest 2008;88:464-73.

62. Sequeiros-Santiago G, Garcia-Carracedo D, Fresno MF, et al. Oncogene amplification pattern in adenoid cystic carcinoma of the salivary glands. Oncol Rep 2009;21:1215-22.
63. Greer R0 Jr, Said S, Shroyer KR, et al. Overexpression of cyclin D1 and cortactin is primarily independent of gene amplification in salivary gland adenoid cystic carcinoma. Oral Oncol 2007:43:735-41.

64. Rao PH, Roberts D, Zhao YJ, et al. Deletion of 1p32-p36 is the most frequent genetic change and poor prognostic marker in adenoid cystic carcinoma of the salivary glands. Clin Cancer Res 2008:14:5181-7.

65. Mark HF, Hanna I, Gnepp DR. Cytogenetic analysis of salivary gland type tumors. Oral Surg Oral Med Oral Pathol Oral Radiol Endod 1996;82:187-92.

66. Patel KJ, Pambuccian SE, Ondrey FG, et al. Genes associated with early development, apoptosis and cell cycle regulation define a gene expression profile of adenoid cystic carcinoma. Oral Oncol 2006;42:994-1004.

67. Frierson HF Jr, El-Naggar AK, Welsh JB, et al. Large scale molecular analysis identifies genes with altered expression in salivary adenoid cystic carcinoma. Am J Pathol 2002;161:1315-23

68. Edwards PC, Bhuiya T, Kelsch RD. C-kit expression in the salivary gland neoplasms adenoid cystic carcinoma, polymorphous low-grade adenocarcinoma, and monomorphic adenoma. Oral Surg Oral Med Oral Pathol Oral Radiol Endod 2003;95:586-93.

69. Holst VA, Marshall CE, Moskaluk CA, et al. KIT protein expression and analysis of c-kit gene mutation in adenoid cystic carcinoma. Mod Pathol 1999;12:956-60.

70. Jeng YM, Lin CY, Hsu HC. Expression of the c-kit protein is associated with certain subtypes of salivary gland carcinoma. Cancer Lett 2000;154:107-11.

71. Volker HU, Scheich M, Berndt A, et al. Expression of p-AKT characterizes adenoid cystic carcinomas of head and neck with a higher risk for tumor relapses. Diagn Pathol 2009;4:18.

72. Mastropasqua MG, Maiorano E, Pruneri G, et al. Immunoreactivity for c-kit and p63 as an adjunct in the diagnosis of adenoid cystic carcinoma of the breast. Mod Pathol 2005; 18:1277-82.

73. Azoulay S, Lae M, Freneaux P, et al. KIT is highly expressed in adenoid cystic carcinoma of the breast, a basal-like carcinoma associated with a favorable outcome. Mod Pathol 2005; 18:1623-31.

74. Crisi GM, Marconi SA, Makari-Judson G, et al. Expression of c-kit in adenoid cystic carcinoma of the breast. Am J Clin Pathol 2005;124:733-9.

75. Rutherford S, Yu Y, Rumpel CA, et al. Chromosome 6 deletion and candidate tumor suppressor genes in adenoid cystic carcinoma. Cancer Lett 2006:236:309-17.

76. Rutherford S, Hampton GM, Frierson HF, et al. Mapping of candidate tumor suppressor genes on chromosome 12 in adenoid cystic carcinoma. Lab Invest 2005;85:1076-85

77. Galloway JR, Woolner LB, Clagett OT. Adenoid cystic carcinoma of the breast. Surg Gynecol Obstet 1966:122:1289-94.

78. Azzopardi JE. Problems in breast pathology. London: WB Saunders, 1979.

79. Wells CA, Nicoll S, Ferguson DJ. Adenoid cystic carcinoma of the breast: a case with axillary lymph node metastasis. Histopathology 1986:10:415-24.

80. Acs G, Simpson JF, Bleiweiss IJ, et al. Microglandular adenosis with transition into adenoid cystic carcinoma of the breast. Am J Surg Pathol 2003;27:1052-60.

81. James BA, Cranor ML, Rosen PP. Carcinoma of the breast arising in microglandular adenosis. Am J Clin Pathol 1993;100:507-13.

82. Khalifeh IM, Albarracin C, Diaz LK, et al. Clinical, histopathologic, and immunohistochemical features of microglandular adenosis and transition into in situ and invasive carcinoma. Am J Surg Pathol 2008;32:544-52.

83. Koenig C, Dadmanesh F, Bratthauer GL, et al. carcinoma arising in microglandular adenosis: an immunohistochemical analysis of 20 intraepithelial and invasive neoplasms. Int J Surg Pathol 2000;8:303-15.

84. Tavassoli FA, Norris HJ. Mammary adenoid cystic carcinoma with sebaceous differentiation. A morphologic study of the cell types. Arch Pathol Lab Med 1986;110:1045-53.

85. Kleer CG, Oberman HA. Adenoid cystic carcinoma of the breast: value of histologic grading and proliferative activity. Am J Surg Pathol 1998;22:569-75.

86. Lamovec J, Us-Krasovec M, Zidar A, et al. Adenoid cystic carcinoma of the breast: a histologic, cytologic, and immunohistochemical study. Semin Diagn Pathol 1989;6:153-64

87. McGuire WL, De La Garza M, Chamness GC. Evaluation of estrogen receptor assays in human breast cancer tissue. Cancer Res 1977;37:637-9.

88. Hayat MA. Microscopy, immunohistochemistry and antigen retrieval methods for light and electron microscopy. New York: Kluwer Academic/Plenum Publisher, 2002.

89. Weigelt B, Baehner FL, Reis-Filho JS. The contribution of gene expression profiling to breast cancer classification, prognostication and prediction: a retrospective of the last decade. J Pathol 2010;220:263-80.

90. Weigelt B, Reis-Filho JS. Histological and molecular types of breast cancer: is there a unifying taxonomy. Nat Rev Clin Oncol 2009:6:718-30.

91. Hu Z, Fan C, Oh DS, et al. The molecular portraits of breast tumors are conserved across microarray platforms. BMC Genomics 2006;7:96.

92. Perou CM, Sorlie T. Eisen MB, et al. Molecular portraits of human breast tumours. Nature 2000;406:747-52.

93. Sorlie T, Tibshirani R, Parker J, et al. Repeated observation of breast tumor subtypes in independent gene expression data sets. Proc Natl Acad Sci U S A 2003;100:8418-23.

94. Sorlie T, Perou CM, Tibshirani R, et al. Gene expression patterns of breast carcinomas distinguish tumor subclasses with clinical implications. Proc Natl Acad Sci U S A 2001;98:10869-74.

95. Peppercorn J, Perou CM, Carey LA. Molecular subtypes in breast cancer evaluation and management: divide and conquer. Cancer Invest 2008;26:1-10. 
96. Reis-Filho JS, Milanezi F, Steele D, et al. Metaplastic breast carcinomas are basallike tumours. Histopathology 2006;49:10-21.

97. Lae M, Freneaux P, Sastre-Garau X, et al. Secretory breast carcinomas with ETV6NTRK3 fusion gene belong to the basal-like carcinoma spectrum. Mod Pathol 2009;22:291-8.

98. Rakha EA, Reis-Filho JS, Ellis I0. Basal-like breast cancer: a critical review. J Clin Oncol 2008;26:2568-81.

99. Weigelt B, Kreike B, Reis-Filho JS. Metaplastic breast carcinomas are basal-like breast cancers: a genomic profiling analysis. Breast Cancer Res Treat 2009; 117:273-80.

100. Reis-Filho JS, Tutt AN. Triple negative tumours: a critical review. Histopathology 2008; 52:108-18

101. Manie E, Vincent-Salomon A, Lehmann-Che J, et al. High frequency of TP53 mutation in BRCA1 and sporadic basal-like carcinomas but not in BRCA1 luminal breast tumors. Cancer Res 2009:69:663-71.

102. Pastolero G, Hanna W, Zbieranowski I, et al. Proliferative activity and p53 expression in adenoid cystic carcinoma of the breast. Mod Pathol 1996:9:215-19.

103. Pandis N, Teixeira MR, Gerdes AM, et al. Chromosome abnormalities in bilateral breast carcinomas. cytogenetic evaluation of the clonal origin of multiple primary tumors. Cancer 1995:76:250-8.

104. Faivre S, Raymond E, Casiraghi 0 , et al. Imatinib mesylate can induce objective response in progressing, highly expressing KIT adenoid cystic carcinoma of the salivary glands. J Clin Oncol 2005;23:6271-3; author reply 6273-4.
105. Lin $\mathbf{C H}$, Yen RF, Jeng YM, et al. Unexpected rapid progression of metastatic adenoid cystic carcinoma during treatment with imatinib mesylate. Head Neck 2005:27:1022-7.

106. Pfeffer MR, Talmi Y, Catane R, et al. A phase II study of Imatinib for advanced adenoid cystic carcinoma of head and neck salivary glands. Oral Oncol 2007:43:33-6.

107. Hotte SJ, Winquist EW, Lamont E, et al. Imatinib mesylate in patients with adenoid cystic cancers of the salivary glands expressing c-kit: a Princess Margaret Hospita Phase II Consortium Study. J Clin Oncol 2005;23:585-90.

108. Slevin NJ, Mais KL, Bruce I, et al. Imatinib with cisplatin in recurrent and/or metastatic salivary adenoidcystic carcinoma-response assessed by FDG-PET scanning [abstract]. J Clin Oncol 2004;22:5604.

109. Hornick JL, Fletcher CD. The role of KIT in the management of patients with gastrointestinal stromal tumors. Hum Pathol 2007;38:679-87.

110. Foschini MP, Reis-Filho JS, Eusebi V, et al. Salivary gland-like tumours of the breast: surgical and molecular pathology. J Clin Pathol 2003;56:497-506.

111. Di Palma S, Skalova A, Ungari M, et al. Pure salivary duct carcinomas can be classified into luminal, Her2 and basal-like phenotypes. Abstract 1072. Mod Pathol 2008;21(Suppl 1).

112. Aparicio SA, Huntsman DG. Does massively parallel DNA resequencing signify the end of histopathology as we know it? J Pathol 2010;220:307-15.

113. Reis-Filho JS. Next generation sequencing. Breast Cancer Res 2009;11(Suppl 3): S12. 